OPEN ACCESS

Edited by: Miguel Herrero, Spanish National Research Council (CSIC), Spain

Reviewed by:

Michael La Frano, California Polytechnic State University, United States Jaime Salcedo Dominguez, University of California, Davis, United States

*Correspondence:

Abdellah Teban abdellah.tebani@yahoo.com

Specialty section:

This article was submitted to

Nutrition Methodology,

a section of the journal

Frontiers in Nutrition

Received: 07 December 2018 Accepted: 21 March 2019

Published: 09 April 2019

Citation:

Tebani A and Bekri S (2019) Paving the Way to Precision Nutrition Through

Metabolomics. Front. Nutr. 6:41. doi: 10.3389/fnut.2019.00041

\section{Paving the Way to Precision Nutrition Through Metabolomics}

\author{
Abdellah Tebani ${ }^{1 *}$ and Soumeya Bekri ${ }^{1,2}$ \\ ${ }^{1}$ Department of Metabolic Biochemistry, Rouen University Hospital, Rouen, France, ${ }^{2}$ Normandie Univ, UNIROUEN, CHU \\ Rouen, INSERM U1245, Rouen, France
}

Nutrition is an interdisciplinary science that studies the interactions of nutrients with the body in relation to maintenance of health and well-being. Nutrition is highly complex due to the underlying various internal and external factors that could model it. Thus, hacking this complexity requires more holistic and network-based strategies that could unveil these dynamic system interactions at both time and space scales. The ongoing omics era with its high-throughput molecular data generation is paving the way to embrace this complexity and is deeply reshaping the whole field of nutrition. Understanding the future paths of nutrition science is of importance from both translational and clinical perspectives. Basic nutrients which might include metabolites are important in nutrition science. Moreover, metabolites are key biological communication channels and represent an appealing functional readout at the interface of different major influential factors that define health and disease. Metabolomics is the technology that enables holistic and systematic analyses of metabolites in a biological system. Hence, given its intrinsic functionality, its tight connection to metabolism and its high clinical actionability potential, metabolomics is a very appealing technology for nutrition science. The ultimate goal is to deliver a tailored and clinically relevant nutritional recommendations and interventions to achieve precision nutrition. This work intends to present an update on the applications of metabolomics to personalize nutrition in translational and clinical settings. It also discusses the current conceptual shifts that are remodeling clinical nutrition practices in this Precision Medicine era. Finally, perspectives of clinical nutrition in the ever-growing, data-driven healthcare landscape are presented.

Keywords: metabolomics, precision nutrition, biomarker, omics, precision medicine

\section{INTRODUCTION: METABOLOMICS AND METABOTYPES}

The metabolome defines the metabolites present in a given organism (1). Metabolomics refers to the analysis of the metabolome of biological system $(2,3)$. Metabolites are small organic molecules involved or not in enzymatic reactions. Thus, metabolomics is a technology that aims to biochemically characterize a metabolome and its changes regarding genetic, environmental, drug, or dietary factors (4). Hence, metabolomics is an appealing tool to define metabotypes (metabolic phenotypes) that could be used for individual stratification. It is well known that metabolic characteristics drive individual differences regarding nutritional requirements and responses to diet and medication $(5,6)$. Thus, based on this metabolic specificity, dietary recommendations could be tailored at the individual level. This high customization is supposed to be more effective in terms of health-care outcomes and costs than conventional general recommendations 
$(5,7)$. These endeavors led to the emergence of the concept of metabotyping or metabolic phenotyping, which stratify individuals based on their metabolic and phenotypic patterns into metabotype subgroups with high metabolic similarity. Thus, this metabolic similarity could be used for population stratification to define tailored dietary or medical intervention $(8-10)$. Two main technologies are used in metabolomics, Nuclear magnetic spectroscopy (NMR) and mass spectrometry (MS) combined or not with a gas phase or liquid phase separation method (11). NMR spectroscopy has the advantage to be nondestructive, rapid, highly reproducible, and robust but it lacks sensitivity. MS-based methods are more sensitive, but they are destructive and might have lower throughput especially if combined with a separation dimension. These techniques recover global, unbiased, and comprehensive chemical information from the assessed biological samples. Metabolomics workflows are based on the previous knowledge of the metabolites to analyze. A targeted approach is defined as a quantitative analysis when absolute concentrations are determined or a semiquantitative analysis when relative intensities are determined for a set of metabolites. The untargeted approach is primarily based on the qualitative or semiquantitative analysis of the most possibly detectable metabolites in the biological sample. Untargeted metabolomics is often used for biomarker discovery studies. Depending on the study, different parameters should be taken into account; defining the metabolomics approach (targeted vs. untargeted), biological samples, sample size, pooling, experimental conditions (i.e., observational studies, exploratory studies, time series), sampling conditions and storage, analytical platforms, and standardized sample preparation procedures. To translate the metabolomics data into actionable information, data analysis. The choice of the most appropriate data analysis strategy depends mostly on the underlying investigation aim. In mechanistic studies, the structure of the data descriptions of the built model are more important than its predictive power to classify new samples. In diagnosis or prognostic applications, the classification performances of the model are crucial. It is also to be noted that sample sizes and model validation using external validation sets are mandatory to avoid overfitting of the models to avoid spurious conclusions (12). In this review we will focus on the use of metabolomics in human studies to achieve personalized nutrition or precision nutrition ( $\mathrm{PN}$ ) which refers to the design of customized nutritional recommendations to prevent or to treat nutrition-related disorders (13).

\section{PATHWAYS TOWARD PRECISION NUTRITION}

\section{Nutritional Research}

Nutritional research focuses on unveiling the interrelationships between diet and health to prevent or treat diet-related disorders (14). It is established that the individual nutritional needs vary largely according to anthropometrics such as age, gender and also on physiological states and other biological and environmental attributes (15). Furthermore, the response to dietary interventions exhibits substantial inter-individual variation. In this era of precision medicine, it is time to tailor dietary intervention and advice at the individual level such as biomarkers related to red meat (16) or bread consumption (17). To effectively understand diet and lifestyle interaction in health and disease, robust, and informative biomarkers for nutritional status are mandatory $(18,19)$. However, different challenges hamper the application of nutritional biomarkers. First, there is no consensus on nutritional biomarker definition, its assessment and use. Furthermore, even the well-validated biomarkers lack consistency to support strong recommendations $(20,21)$. To overcome these constraints, several initiatives have been launched to promote the identification and development of new nutritional biomarkers by defining methods, conditions, and settings of nutritional biomarker quantification to set standardized and actionable protocols $(22,23)$. In addition to this organizational and strategic endeavors, deep and extensive research is still mandatory to provide a deep molecular understanding of nutrients effects on health and disease. Recently, a comprehensive definition of personalized nutrition has emerged that describes three main levels in precision nutrition: level $\mathbf{1}$ is dietary advice based on dietary intake; level 2 adds to level 1 phenotypic metrics and laboratory tests; level 3 goes deep by adding, to the previous levels, the genetic information layer (22). Large-scale initiatives such as the Food4me performed randomized control trial to assess improvements in personalized dietary advice compared to conventional approaches (7). The results showed changes in dietary behavior related to customized nutritional advice. However, from a public health perspective, these results are hard to scale up. This work intends to present an update on the applications of metabolomics to personalize nutrition in translational and clinical settings. It also discusses the current conceptual shifts that are remodeling clinical nutrition practices in this Precision Medicine era.

\section{Traditional Dietary Assessment Techniques and Their Limitations}

For decades, nutritional research has been a crucial pillar to unveil diet-health relationships at both individual and population scale. However, consistency, validation and reproducibility of the dietary assessments have been the great challenges (19). For a long time, food diaries, $24 \mathrm{~h}$ recalls and Food Frequency Questionnaire (FFQ) are used as self-report dietary assessment methods in human nutrition studies (24). Multiple days weighted food records are often used in controlled dietary studies (25). However, these dietary records are time consuming and tedious for both participants and investigators, and lack accuracy and consistency $(25,26)$ which limits their integration in large-scale studies. Alternatives such as $24 \mathrm{~h}$ recalls may be used. This method may include a structured collection of detailed information about food intake during the previous $24 \mathrm{~h}$. A major drawback is that these recalls are subjected to inter-day nutritional variation (25). For largescale studies, self-administered FFQ are preferred to evaluate food intake. All these methods (food records, recalls, and FFQ) require an intensive preparation before implementation. 
However, the managing and processing of a well-validated FFQ is rather smooth for large studies. Still, inaccurate portion size estimation, socially distorted answers, lack of objectivity and accuracy in self-reported data, and errors in food intake composition hamper FFQ and make it prone to record errors $(27,28)$. The implementation of high-throughput omics tools enables the holistic and integrative interrogation of nutrition by identifying nutrition-specific biomarkers to objectively assess dietary intake. These biomarkers may provide actionable information to fill in the gaps of self-reported food intake given the tight connection between metabolite production, food intake, the microbiome, and health status (29). Indeed, stratification of individuals into groups can be achieved through the analysis of their respective metabolic profiles. This approach of grouping subjects based on their metabolic phenotype was coined "metabotyping" and has been used in several of studies $(30,31)$. This review will examine this concept in the field of personalized nutrition.

\section{Pathways Toward Precision Nutrition}

The goal of precision or personalized nutrition (PN) is the design of customized nutritional recommendations to prevent or to treat nutrition-related disorders (13). PN aims to set dynamic nutritional recommendations based on individual attributes and external environmental factors. Hence, PN strategies should include genomics information, other factors such as dietary and physical activity patterns, metabolome, and microbiota. The post-genomic era generated various genome-wide association studies (GWAS) that allow the identification of genomic factors that might unveil the inter-individual metabolic response variability to specific diets. Various genes and polymorphisms have been defined as relevant factors to explain diet-specific metabolic responses (32-36). However, there is weak clinical evidence to establish comprehensive and integrated framework for personalized nutritional interventions in clinical settings (37). Despite this, different successful implementations already made it to the clinic. For example, in inborn errors of metabolism (IEM) which are a group of about 500 rare genetic diseases due to defects in a given biochemical pathway due to the deficiency or abnormality of an enzyme, its cofactor, or a transporter, leading to an accumulation of the substrate or lack of the product. In IEM, nutritional strategies are crucial in treatment of some disease such as phenylketonuria screening (38). Interventional nutrition has allowed the implementation of specific diet and saved patients from devastating outcomes for them and their families. In the wellness sphere, genetic tests are used to define slow or fast metabolizers (33). While genomicbased customized nutrition is already being implemented, PN might lack sufficient evidence for full integration into clinical setting (39).

\section{METABOLOMICS AS A KEY ENABLER OF PRECISION NUTRITION}

Metabolomics is a key tool to investigate the effect of food on the individual's health. By identifying food-derived biomarkers, inter-individual variability in metabolizing same foods in health and disease states. Metabolomics could enhance nutrition assessment through three main pathways: dietary intake biomarker discovery, diet-related diseases exploration through cohort studies, and dietary intervention assessment through metabolic patterns. A summary of discussed studies are presented in Table 1.

\section{Dietary Intake Biomarker Discovery Using Intervention Studies}

Dietary intervention studies are based on consuming specific food followed by biofluid collection either postprandial or following a short-term intervention (54). Urine is the most used biological sample due to its convenience compared to plasma and serum. This strategy unveiled potential food intake biomarkers such as citrus fruit (40), red meat (41), coffee (42), tea (43), sugar-sweetened beverages (44), and wine (45). Even though, several food specific biomarkers have been reported they still lack independent large-scale validation studies. It also worth noting that most of these biomarkers are rapidly secreted in urine. Thus, they are mostly acute food intake biomarkers. Hence, given this temporal limit, longer-term biomarkers of food intake are crucially needed. Currently, an increasing number of studies are assessing biomarkers in serum and plasma.

\section{Dietary Biomarker Discovery Using Cohort Studies}

Large-scale cohort studies are also valuable tools to discover dietary biomarkers. Dietary data may be collected using traditional methods to identify consumer profiles related to specific food (e.g., low and high consumers, consumers, and nonconsumers). In this case, metabolomic profiles are compared between these subgroups to unveil potential dietary biomarkers. Given their practicability, Self-reported dietary assessment methods are often used in large-scale studies tend to rely on which are known to be notoriously prone to error. It is worth noting these studies are mainly association studies and don't allow causal inference (55). Intervention studies are, therefore, needed to validate the potential metabolite as a specific food intake biomarker. Several cohort studies identified intake biomarkers such as fish (46), red meat $(16,56)$, whole-grain bread (17), and walnuts (47). Furthermore, metabolomics has also been used in populational stratification (57-59). Recently, Wittenbecher et al. (16) applied serum metabolomics to unveil significant relationships between different red meat intake biomarkers with risk of type-2 diabetes. The authors state that high levels of ferritin, low glycine, and altered hepatic derived lipids in the circulation were associated with both total red meat consumption and diabetes risk. This first study assessing a large set of metabolites revealed the link between red meat intake and diabetes risk and thus achieved an important step in biomarker discovery in precision nutrition. Unveiling these links between will allow deeper understanding potential metabolic pathways as disease drivers. These pathways could be validated through more interventional nutrition studies using targeted approaches for biomarker validation. 
TABLE 1 | Examples of metabolomics-based studies in nutritional research.

\begin{tabular}{|c|c|c|c|c|}
\hline Groups & Platform & Aim & Main findings & References \\
\hline \multicolumn{5}{|c|}{ DIETARY INTAKE BIOMARKER DISCOVERY USING INTERVENTION STUDIES } \\
\hline $\begin{array}{l}8 \text { healthy males } \\
18-50 \text { years old }\end{array}$ & $\begin{array}{l}\text { Fluorescence detection } \\
\text { Targeted metabolomics }\end{array}$ & $\begin{array}{l}\text { To compare the effects of citrus } \\
\text { dietary levels of proline betaine } \\
\text { on glycine betaine excretion, and } \\
\text { on plasma total homocysteine } \\
\text { and betaine concentrations in } \\
\text { healthy volunteers }\end{array}$ & $\begin{array}{l}\text { Proline and betaine in dietary levels had little } \\
\text { effect on plasma total homocysteine } \\
\text { concentrations in healthy humans. }\end{array}$ & $(40)$ \\
\hline $\begin{array}{l}7 \text { females and } 1 \text { male } \\
28-45 \text { years old }\end{array}$ & $\begin{array}{l}\text { NMR untargeted } \\
\text { metabolomics }\end{array}$ & $\begin{array}{l}\text { Identification of coffee } \\
\text { consumption biomarkers }\end{array}$ & $\begin{array}{l}\text { 2-furoylglycine as a putative biomarker for } \\
\text { coffee consumption }\end{array}$ & $(42)$ \\
\hline $\begin{array}{l}35 \text { healthy males } \\
18-69 \text { years old }\end{array}$ & $\begin{array}{l}\text { Untargeted and targeted } \\
\text { metabolomics } \\
\text { Mass spectrometry } \\
\text { and NMR }\end{array}$ & $\begin{array}{l}\text { Identification of wine } \\
\text { consumption biomarkers }\end{array}$ & $\begin{array}{l}\text { Red wine and grape juice consumption alters } \\
\text { microbial fermentation and amino acid } \\
\text { metabolism }\end{array}$ & $(45)$ \\
\hline \multicolumn{5}{|c|}{ DIETARY BIOMARKER DISCOVERY USING COHORT STUDIES } \\
\hline $\begin{array}{l}33 \text { males and } 35 \text { females } \\
58-60 \text { years old }\end{array}$ & $\begin{array}{l}\text { Untargeted mass } \\
\text { spectrometry metabolomics }\end{array}$ & $\begin{array}{l}\text { To develop a data-driven } \\
\text { procedure to discover urine } \\
\text { biomarkers indicative of habitual } \\
\text { exposure to different foods }\end{array}$ & $\begin{array}{l}\text { Specific metabolites as dietary biomarkers of } \\
\text { oily fish [methyl-histidine] and coffee } \\
\text { [dihydrocaffeic acid derivatives] }\end{array}$ & $(46)$ \\
\hline $\begin{array}{l}275 \text { males ( } 55-80 \text { years) } \\
\text { and females (60-80 years) }\end{array}$ & $\begin{array}{l}\text { Untargeted mass } \\
\text { spectrometry metabolomics }\end{array}$ & $\begin{array}{l}\text { To characterize the dietary } \\
\text { walnut fingerprinting }\end{array}$ & $\begin{array}{l}18 \text { metabolites, including markers of fatty acid } \\
\text { metabolism, ellagitannin-derived microbial } \\
\text { compounds, and intermediate metabolites of } \\
\text { the tryptophan/serotonin pathway }\end{array}$ & $(47)$ \\
\hline \multicolumn{5}{|c|}{ DIETARY BIOMARKER DISCOVERY USING DIETARY PATTERNS } \\
\hline $\begin{array}{l}24 \text { healthy premenopausal } \\
\text { females } \\
20-50 \text { years old }\end{array}$ & Targeted metabolomics & $\begin{array}{l}\text { To identify typical and atypical } \\
\text { metabolite temporal patterns in } \\
\text { response to paired meal } \\
\text { challenge tests. }\end{array}$ & $\begin{array}{l}\text { Three subgroups related to insulin resistance } \\
\text { and leptin levels are identified }\end{array}$ & $(48)$ \\
\hline $\begin{array}{l}12 \text { males and } 12 \text { females } \\
36-69 \text { years old }\end{array}$ & $\begin{array}{l}\text { Ultraviolet detection } \\
\text { targeted metabolomics }\end{array}$ & $\begin{array}{l}\text { Assessed the response to } \\
\text { dietary carotenoids in juice } \\
\text { (watermelon and tomato) }\end{array}$ & $\begin{array}{l}\text { Five metabolic subgroups with related to } \\
\text { dietary. This study identified strong and weak } \\
\text { metabolizers of carotenoids over time }\end{array}$ & $(49)$ \\
\hline $\begin{array}{l}740 \text { males and } 760 \text { females } \\
18-90 \text { years old }\end{array}$ & $\begin{array}{l}\text { Mass spectrometry targeted } \\
\text { metabolomics }\end{array}$ & $\begin{array}{l}\text { Assessment of demographics, } \\
\text { dietary habits, and metabotype }\end{array}$ & $\begin{array}{l}\text { Two subgroups were identified regarding } \\
\text { fasting metabolic profile and the postprandial } \\
\text { insulin levels. }\end{array}$ & $(50)$ \\
\hline $\begin{array}{l}19 \text { postmenopausal finish } \\
\text { females } \\
56-66 \text { years old }\end{array}$ & $\begin{array}{l}\text { Untargeted mass } \\
\text { spectrometry }\end{array}$ & $\begin{array}{l}\text { Assessment of metabolic } \\
\text { phenotypes in a randomized } \\
\text { controlled, crossover meal study }\end{array}$ & $\begin{array}{l}\text { Medium- to long-chain acylcarnitines shows } \\
\text { opposite patterns related to fruits and desert } \\
\text { intake. Whereas, short-chain acylcarnitines and } \\
\text { amino acids, were positively correlated with } \\
\text { saturated fat }\end{array}$ & $(51)$ \\
\hline
\end{tabular}


TABLE 1 | Continued

\begin{tabular}{|c|c|c|c|c|}
\hline Groups & Platform & Aim & Main findings & References \\
\hline $\begin{array}{l}79 \text { females } 28 \text { males } \\
18-65 \text { years old }\end{array}$ & $\begin{array}{l}\text { Untargeted mass } \\
\text { spectrometry }\end{array}$ & $\begin{array}{l}\text { Developing a compliance tool by } \\
\text { using metabotyping strategies by } \\
\text { comparing average Danish Diet } \\
\text { or a New Nordic Diet for } 6 \\
\text { months }\end{array}$ & $\begin{array}{l}22 \text { unique food exposure markers were } \\
\text { identified that covered } 7 \text { food groups } \\
\text { (strawberry, cabbages, beetroot, walnut, citrus, } \\
\text { green beans, and chocolate) }\end{array}$ & (52) \\
\hline $\begin{array}{l}16 \text { females } 21 \text { males } \\
18-50 \text { years old }\end{array}$ & $\begin{array}{l}\text { Targeted mass } \\
\text { spectrometry }\end{array}$ & $\begin{array}{l}\text { Assessment Western and } \\
\text { Prudent dietary patterns on } \\
\text { metabotypes }\end{array}$ & $\begin{array}{l}\text { Western dietary pattern is related to saturated } \\
\text { fat intakes with a metabolic signature } \\
\text { characterized by higher levels of short-chain } \\
\text { acylcarnitines and amino acids including } \\
\text { branched amino acids and aromatic amino } \\
\text { acids }\end{array}$ & (53) \\
\hline
\end{tabular}

\section{Dietary Biomarker Discovery Using Dietary Patterns}

O'Sullivan et al. pioneered the combination of dietary patterns and metabolomic patterns (60). Then, this approach has been widely used in several studies $(53,61-64)$. It generally involves applying chemometrics and multivariate statistical strategies to model the metabolic patterns and the food intake behavior. Different methods could be used. Unsupervised learning methods are exploratory and are used to define metabolically similar groups. The methods included $\mathrm{k}$-means cluster analysis (65-70), hierarchical clustering (71-73), self-organizing maps (74), principal component analysis (PCA) $(48,51)$, factor analysis (70), and mixed effect modeling $(75,76)$. Supervised learning methods are predictive and are used to select biomarkers to predict diet related metabolic patterns. Among these methods partial least squares regression is widely used $(51,77)$. Univariate statistics such as $t$-test and ANOVA, can also be used to find discriminant features between the studied groups. It is worth noting that cross-validation and the use of training and validation sets are crucial for model validation. Krishnan et al. (48) used metabolomics to stratify response groups to meals with different glycemic indices. The study included 24 healthy premenopausal women aged between 20 and 50 years old. The authors assessed blood glucose, insulin, and leptin as covariates. The study revealed three distinct biologically meaningful subgroups one with higher insulin resistance and the other with higher leptin levels (48). Wang et al. assessed the response to dietary carotenoids in juice (watermelon and tomato) including 23 healthy subjects (49). Dynamic response of individual plasma carotenoids has been assessed. The study revealed five metabolic subgroups with related to dietary carotenoids. This study identified strong and weak metabolizers of carotenoids over time. The different responses seem to be induced by genetic variants of the carotenoid metabolizing enzyme $\beta$-carotene 15,15'-monooxygenase 1 (49). $\mathrm{Li}$ et al. (50) from the Irish National Adult Nutrition Survey (NANS) included 1,500 participants (740 males and 760 females) aged between 18 and 90 years. This study assessed habitual food and beverage consumption in an Irish cohort. The authors assessed 26 plasma fatty acids and identified four subgroups with distinct fatty acid patterns related to demographics, dietary habits, and metabotype (50). Moazzami et al. assessed metabolic phenotypes in a randomized, controlled, crossover meal study including 19 postmenopausal finish women with mean age of 61 years. One hundred eighty-nine metabolites were assessed (51). Two metabolic subgroups were identified regarding fasting metabolic profiles and the postprandial insulin levels. Despite similar glycaemia after bread intake, plasma leucine, isoleucine, sphingomyelins, and phosphatidylcholines were associated with insulin sensitivity. The authors suggest the use of fasting metabotypes to probe the postprandial insulin behaviors in individuals with normal glycaemia to stratify population (51). Andersen et al. aimed to develop a compliance tool by using metabotyping strategies (52). The authors have applied untargeted metabolomics on 181 urine samples from subject assigned to either an Average Danish Diet or a New Nordic Diet for 6 months. The data resulted in a predictive model used to track non-compliant subjects. This study shows how metabolomics could help to build metabolic predictors to follow complex diets compliance as long as metabolites are quantitatively assessed and the multivariate models are robustly validated. Dietary patterns may also help in studying diet and disease interrelationships. Bouchard-Mercier et al. studied in 37 plasma, using targeted metabolomics, the metabotypes associated with the Western and Prudent dietary patterns. The data suggest that medium- to long-chain acylcarnitines show opposite patterns related to fruits and desert intake. Whereas, shortchain acylcarnitines and amino acids, were positively correlated with saturated fat (53). These studies show the potential of metabolomics is not only a tool dietary pattern compliance, but also to identify and assess diet and disease relationships (78-80).

\section{INTERROGATING MICROBIOTA-DIET CROSS TALKS THROUGH METABOLOMICS}

Gut microbiota profiling is gaining great interest in nutritional interventions to assess dietary effects on gut microbiome ecosystem diversity (81). The core idea is to tailor nutritional interventions by optimizing the richness and diversity of the gut microbiota (82). Diet may effect on the gut microbiota and its impact on the microbial metabolome is very appealing. 
Diet may serve as a substrate that can be processed by the gut microbiota for the production of small molecules to sustain host-microbiome interactions (83-85). For example, it has been reported that the majority of microbiota-derived short-chain fatty acids is absorbed by the host (86) and contributes to host nutrition (87). The FRUVEDomics Study is a behavioral interventional trial. It aims to identify metabolomics- and microbiome-based nutritional risk factors. The study included 36 participants that were randomized into three intervention groups, fruits and vegetables diet, associated either with low-fat or low carbohydrates (88). The results suggested that metabolic syndrome is correlated to higher Firmicutes to Bacteroidetes ratio (88). Other studies highlight the relevance of interrogating the gut microbiota to achieve precision nutrition $(89,90)$. These studies suggest that increased fasting plasma levels of trimethylamine (TMA), produced by gut microbiota, is associated with increased risk of atherosclerosis. These studies led to targeted recommendations of nutrition advice such as reducing red meat intake (91) for subjects with gut microbial ecosystem that could convert red meat related nutrients into proatherogenic molecules. Other general recommendations may also be questioned, such as using artificial sweeteners, as reported by Suez et al. (92) who reported that high sweetener intake may lead to glucose intolerance in subjects with sensitive gut microbiota (92). However, their results seem to be controversial given the used high dose of sweetener $(93,94)$. Another way to take advantage of this microbiota-host interaction through diet and thus, through metabolites, is to use prebiotics which are substrates that are selectively and used by host microorganisms and led to better health for the host. They are another appealing mean to take advantage of microbiome modulation (95). Some studies suggest a potential therapeutic use of prebiotics (9699). For example, fiber-rich diet is associated with an increased Prevotella/Bacteroides ratios and improved glucose metabolism (100). However, diet is a highly diverse biochemical space, often tuned by the microbiota (101). Thus, dietary interventions may be personalized based on this fine-tuning of microbiome of diet (102). Zeevi et al. used an elegant strategy integrating microbiome, clinical, and dietary data to build predictive models to shape customized dietary recommendations for healthier glycaemia (18). Using genome-scale metabolic modeling, Shoaie et al. elegantly modeled the interactions of diet, gut microbiota, and host metabolism. The authors successfully predicted microbiome metabolic responses related to a dietary intervention in obese subjects and formally validated their predictions using fecal and blood metabolomics data (103). Given this microbiota plasticity, microbiome-targeted interventions are very appealing approach to personalize diet intervention. However, this microbiota plasticity may be dependent on previous dietary habits (104) and baseline microbial populations, which could hamper microbiota-directed intervention responses (105). Thus, high resolution definition of key diet-responsive microbiome is very important to enhance the prediction performance of dietary interventions. Despite current challenges that hamper effective clinical translation of microbiota-related to nutrition interventions, new analytical, and computational developments may help overcome these limits. Indeed, its integration with other omics such as proteomics and metabolomics for better and more accurate functional profiling $(18,106)$. However, still largescale studies are needed to draw robust conclusions. Moreover, controlled studies are mandatory to characterize environmental factors independent of diet which may be crucial in modeling the gut microbiota ecosystem. These evidence-based requirements will help to open promising opportunities in designing personalized nutritional strategies to shape the precision nutrition era.

\section{PRECISION NUTRITION THROUGH INTEGRATIVE OMICS}

As above mentioned, food patterns and eating behaviors are extremely complex that include multilayer informational flows (107). Gene-diet interactions might play a role in the development of and protection against chronic diseases (108). For example, the antioxidant content of the Mediterranean diet could a protective mechanism since antioxidants modulate gene expression (109). It is well known that oxidation and inflammation processes are interconnected and may contribute to different diseases the physiopathology (110). Epigenetics explores heritable DNA modifications that may regulate chromosome architecture to modulate gene expression without changing the underlying sequence (111). Epigenetic phenomena are critical for along the whole lifespan. Different studies confirm the complex interactions that exist among food components, dietary patterns, and epigenetic modifications (112, 113). Lillycrop et al. reported the effect of nutrition through the life span and how in early life nutritional exposure can induce longterm changes in DNA methylation (114). Petersen et al. reported strong influences of genetic variants on metabotypes which shows the relevant exploration of the interconnection between metabolomics and gene regulation through epigenetics (115). This confirms that integrating metabolomics to other omics might be of a great interest in both translational and clinical level. Given this biological complexity, systematically tracking relationships between diet and diseases through multiomics lences is very challenging $(116,117)$. So, innovative systematic strategies are urgently needed to unveil the role of food types in disease pathogenesis for, ultimately, design dietary recommendation to promote health and wellbeing or to cure diseases. Some efforts are already promising. For example, Zheng et al. proposed a computational framework for establishing diet-disease associations and additional information on the role of diet in disease development. The authors used large-scale gene expression datasets and network-based analyses to identify diet-disease relationships that could be used to build dietary recommendations tools (118). Jensen et al. proposed a platform to explore dietary recommendations in association with drugs by building food-drug association database (119). Zeevi et al. proposed an appealing and actionable integration of microbiome, clinical, and dietary data to customize dietary recommendations to tightly monitor glycemia (18). However, large-scale multiomic nutritional intervention studies are rare. The current high cost for multi-omics large-scale dataset generation and 
the lack of streamlined pipelines for smooth integration of the heterogeneous datasets hamper the development of such studies.

\section{CHALLENGES AND FUTURE PERSPECTIVES TOWARD PRECISION NUTRITION}

One of the raised limits of PN is that most studies are observational rather than from randomized controlled trials (RCTs) with assessed clinical end points. Limited information is so far available to confirm that PN produce more accurate and sustained changes in behavior than currently used approaches and do these PN strategies led to better health $(7,19,120)$. So far, no large scale and long term personalized nutrition study has been carried out $(19,121)$. The logistical burden and costs of large-scale nutrition intervention studies with disease risk as outcomes hamper their implementation. Thus, the use of diet changes, or established biomarkers of disease (glycated hemoglobin Alc, blood pressure, or cognitive assessment) as outcomes may be potential surrogates (121). Advancement of the young discipline of PN, including metabotyping, will require new perspectives. Setting strong theoretical foundations by identifying key individual attributes that drive the personalization process. Evidence for cost effectiveness of well-designed interventional studies is also fundamental. Moreover, the introduction of a regulatory framework is mandatory to gain trust of health professionals and policy makers and enhance public protection. This will need a substantial enhancement in the scientific evidence using robust random control trials. These efforts should include multidisciplinary teams, comprising clinicians, behavioral psychologists, nutritionists, computer scientists, and biomedical scientists (19). Furthermore, the integration of other "omics" to provide deeper mechanistic

\section{REFERENCES}

1. Oliver SG, Winson MK, Kell DB, Baganz F. Systematic functional analysis of the yeast genome. Trends Biotechnol. (1998) 16:373-8. doi: 10.1016/S0167-7799(98)01214-1

2. Nicholson JK, Lindon JC, Holmes E. "Metabonomics": understanding the metabolic responses of living systems to pathophysiological stimuli via multivariate statistical analysis of biological NMR spectroscopic data. Xenobiotica. (1999) 29:1181-9.

3. Fiehn O. Metabolomics-the link between genotypes and phenotypes. Plant Mol Biol. (2002) 48:155-71. doi: 10.1023/A:1013713905833

4. Beger RD, Dunn W, Schmidt MA, Gross SS, Kirwan JA, Cascante M, et al. Metabolomics enables precision medicine:"a white paper, community perspective". Metabolomics. (2016) 12:149. doi: 10.1007/s11306-016-1094-6

5. O’Donovan CB, Walsh MC, Gibney MJ, Gibney ER, Brennan L. Can metabotyping help deliver the promise of personalised nutrition? Proc Nutr Soc. (2015) 75:106-14. doi: 10.1017/S0029665115002347

6. Holmes E, Wilson ID, Nicholson JK. Metabolic phenotyping in health and disease. Cell. (2008) 134:714-7. doi: 10.1016/j.cell.2008. 08.026

7. Celis-Morales C, Livingstone KM, Marsaux CF, Macready AL, Fallaize R, O'Donovan $\mathrm{CB}$, et al. Effect of personalized nutrition on health-related insights will be crucial to improve the evidence of precision nutrition $(103,122)$.

\section{CONCLUSION}

Metabolomics proved to be a valuable tool for the measurement of biochemical changes associated health changes related to diet. It is also, highly, promising in identification of nutritional biomarkers to monitor nutritional intervention studies. The greatest challenge for metabolomics research is its integration with other omics and phenotypic data (123). However, better standardization of metabolomics data is mandatory to effectively implement its functional and operational integration. This will enhance our knowledge of diet-health relationships. Nutrition research is intrinsically multidisciplinary, and so is metabolomics. It requires collaboration among research scientists with overlapping expertise areas including nutritionists, clinicians, nurses, bioinformaticians, analytical scientists, statisticians and chemists, and many other stakeholders. This expertise integration is vital to develop the knowledge to establish the evidence-based precision nutrition. The greatest challenge to cracking the relationships between food and health is to decipher the high inter-individual variability responses to food intake. The new frontier of the nutritional sciences lies in our ability to predictably engineer our physiologic networks for diet, health, and disease. This will ultimately allow fine tuning of diet intervention and health monitoring (18). Efforts must be done to support evidence-based nutritional research and achieve effective diet-based disease prevention.

\section{AUTHOR CONTRIBUTIONS}

AT performed literature search and drafted the manuscript. SB critically revised and edited the manuscript. All authors approved the final manuscript. behaviour change: evidence from the Food4Me European randomized controlled trial. Int J Epidemiol. (2017) 46:578-88. doi: 10.1093/ije/ dyw186

8. Brennan L. Use of metabotyping for optimal nutrition. Curr Opin Biotechnol. (2017) 44:35-8. doi: 10.1016/j.copbio.2016.10.008

9. O'Gorman A, Brennan L. The role of metabolomics in determination of new dietary biomarkers. Proc Nutr Soc. (2017) 76:295-302. doi: $10.1017 /$ S0029665116002974

10. Ulaszewska MM, Weinert CH, Trimigno A, Portmann R, Andres Lacueva C, Badertscher R, et al. Nutrimetabolomics: an integrative action for metabolomic analyses in human nutritional studies. Mol Nutr Food Res. (2019) 63:e1800384. doi: 10.1002/mnfr.201800384

11. Tebani A, Afonso C, Bekri S. Advances in metabolome information retrieval: turning chemistry into biology. Part I: analytical chemistry of the metabolome. J Inherit Metabol Dis. (2018) 41:379-91. doi: 10.1007/s10545-017-0074-y

12. Tebani A, Afonso C, Bekri S. Advances in metabolome information retrieval: turning chemistry into biology. Part II: biological information recovery. J Inherit Metab Dis. (2018) 41:393-406. doi: 10.1007/s10545-0170080-0

13. Betts JA, Gonzalez JT. Personalised nutrition: what makes you so special? Nutr Bull. (2016) 41:353-9. doi: 10.1111/nbu.12238 
14. Ohlhorst SD, Russell R, Bier D, Klurfeld DM, Li Z, Mein JR, et al. Nutrition research to affect food and a healthy life span. J Nutr. (2013) 143:1349-54. doi: $10.3945 /$ jn.113.180638

15. Heber D, Berdanier CD, Dwyer JT. Handbook of Nutrition and Food. Boca Raton, FL: CRC Press (2016).

16. Wittenbecher C, Mühlenbruch K, Kröger J, Jacobs S, Kuxhaus O, Floegel A, et al. Amino acids, lipid metabolites, and ferritin as potential mediators linking red meat consumption to type 2 diabetes. Am J Clin Nutr. (2015) 101:1241-50. doi: 10.3945/ajcn.114.099150

17. Garcia-Aloy M, Llorach R, Urpi-Sarda M, Tulipani S, Salas-Salvadó J, Martínez-González MA, et al. Nutrimetabolomics fingerprinting to identify biomarkers of bread exposure in a free-living population from the PREDIMED study cohort. Metabolomics. (2015) 11:155-65. doi: 10.1007/s11306-014-0682-6

18. Zeevi D, Korem T, Zmora N, Israeli D, Rothschild D, Weinberger A, et al. Personalized nutrition by prediction of glycemic responses. Cell. (2015) 163:1079-94. doi: 10.1016/j.cell.2015.11.001

19. Trepanowski JF, Ioannidis JPA. Perspective: limiting dependence on nonrandomized studies and improving randomized trials in human nutrition research: why and how. Adv Nutr. (2018) 9:367-77. doi: 10.1093/advances/nmy014

20. Combs GF Jr, Trumbo PR, McKinley MC, Milner J, Studenski S, Kimura T, et al. Biomarkers in nutrition: new frontiers in research and application. Ann N Y Acad Sci. (2013) 1278:1-10. doi: 10.1111/nyas.12069

21. Raiten DJ, Namasté S, Brabin B, Combs G Jr, L'Abbe MR, Wasantwisut E, et al. Executive summary-biomarkers of nutrition for development: building a consensus. Am J Clin Nutr. (2011) 94:633S-50S. doi: 10.3945/ajcn.110.008227

22. Gibney MJ, Walsh MC. The future direction of personalised nutrition: my diet, my phenotype, my genes. Proc Nutr Soc. (2013) 72:219-25. doi: 10.1017/S0029665112003436

23. Ferguson LR, De Caterina R, Görman U, Allayee H, Kohlmeier M, Prasad C, et al. Guide and position of the international society of nutrigenetics/nutrigenomics on personalised nutrition: part 1 - fields of precision nutrition. Lifestyle Genomics. (2016) 9:12-27. doi: $10.1159 / 000445350$

24. Park Y, Dodd KW, Kipnis V, Thompson FE, Potischman N, Schoeller DA, et al. Comparison of self-reported dietary intakes from the Automated Self-Administered 24-h recall, 4 -d food records, and food-frequency questionnaires against recovery biomarkers. Am J Clin Nutr. (2018) 107:8093. doi: 10.1093/ajcn/nqx002

25. Garden L, Clark H, Whybrow S, Stubbs RJ. Is misreporting of dietary intake by weighed food records or 24-hour recalls food specific? Eur J Clin Nutr. (2018) 72:1026-34. doi: 10.1038/s41430-018-0199-6

26. Yuan C, Spiegelman D, Rimm EB, Rosner BA, Stampfer MJ, Barnett JB, et al. Validity of a dietary questionnaire assessed by comparison with multiple weighed dietary records or 24-hour recalls. Am J Epidemiol. (2017) 185:57084. doi: 10.1093/aje/kww104

27. Thompson FE, Subar AF. Dietary Assessment Methodology, Nutrition in the Prevention and Treatment of Disease. 3rd ed. Amsterdam: Elsevier (2013). p. 5-46. doi: 10.1016/B978-0-12-391884-0.00001-9

28. Freedman LS, Schatzkin A, Midthune D, Kipnis V. Dealing with dietary measurement error in nutritional cohort studies. J Natl Cancer Institute. (2011) 103:1086-92. doi: 10.1093/jnci/djr189

29. McClave SA, Martindale RG. Why do current strategies for optimal nutritional therapy neglect the microbiome? Nutrition. (2019) 60:100-5. doi: 10.1016/j.nut.2018.09.024

30. Bekri S. The role of metabolomics in precision medicine. Expert Rev Precis Med Drug Dev. (2016) 1:517-32. doi: 10.1080/23808993.2016. 1273067

31. Tebani A, Abily-Donval L, Afonso C, Marret S, Bekri S. Clinical metabolomics: the new metabolic window for inborn errors of metabolism investigations in the post-genomic era. Int J Mol Sci. (2016) 17:1167. doi: 10.3390/ijms17071167

32. McMahon G, Taylor AE, Smith GD, Munafo MR. Phenotype refinement strengthens the association of AHR and CYP1A1 genotype with caffeine consumption. PLoS ONE. (2014) 9:e103448. doi: 10.1371 /journal.pone. 0103448
33. Cornelis MC, El-Sohemy A, Campos H. Genetic polymorphism of the adenosine A2A receptor is associated with habitual caffeine consumption. Am J Clin Nutr. (2007) 86:240-4. doi: 10.1093/ajcn/86.1.240

34. Rudkowska I, Pérusse L, Bellis C, Blangero J, Després J-P, Bouchard C, et al. Interaction between common genetic variants and total fat intake on lowdensity lipoprotein peak particle diameter: a genome-wide association study. Lifestyle Genomics. (2015) 8:44-53. doi: 10.1159/000431151

35. Tremblay BL, Cormier H, Rudkowska I, Lemieux S, Couture P, Vohl M-C. Association between polymorphisms in phospholipase A 2 genes and the plasma triglyceride response to an n-3 PUFA supplementation: a clinical trial. Lipids Health Dis. (2015) 14:12. doi: 10.1186/s12944-015-0009-2

36. Ferguson LR. Genome-wide association studies and diet. World Rev Nutr Diet. (2010) 101:8-14. doi: 10.1159/000314505

37. Ahmadi KR, Andrew T. Opportunism: a panacea for implementation of whole-genome sequencing studies in nutrigenomics research? Genes Nutr. (2014) 9:387. doi: 10.1007/s12263-014-0387-5

38. Vockley J, Andersson HC, Antshel KM, Braverman NE, Burton BK, Frazier DM, et al. Phenylalanine hydroxylase deficiency: diagnosis and management guideline. Genet Med. (2014) 16:188. doi: 10.1038/gim.2013.157

39. Camp KM, Trujillo E. Position of the Academy of Nutrition and Dietetics: nutritional genomics. J Acad Nutr Diet. (2014) 114:299-312. doi: 10.1016/j.jand.2013.12.001

40. Atkinson W, Downer P, Lever M, Chambers ST, George PM. Effects of orange juice and proline betaine on glycine betaine and homocysteine in healthy male subjects. Eur J Nutr. (2007) 46:446-52. doi: 10.1007/s00394-007-0684-5

41. Cross AJ, Major JM, Sinha R. Urinary biomarkers of meat consumption. Cancer Epidemiol Prevent Biomarkers. (2011) 20:1107-11. doi: 10.1158/1055-9965.EPI-11-0048

42. Heinzmann SS, Holmes E, Kochhar S, Nicholson JK, Schmitt-Kopplin P. 2Furoylglycine as a candidate biomarker of coffee consumption. J Agric Food Chem. (2015) 63:8615-21. doi: 10.1021/acs.jafc.5b03040

43. van Velzen EJ, Westerhuis JA, van Duynhoven JP, van Dorsten FA, Grun $\mathrm{CH}$, Jacobs DM, et al. Phenotyping tea consumers by nutrikinetic analysis of polyphenolic end-metabolites. J Proteome Res. (2009) 8:3317-30. doi: $10.1021 /$ pr801071p

44. Gibbons H, McNulty BA, Nugent AP, Walton J, Flynn A, Gibney MJ, et al. A metabolomics approach to the identification of biomarkers of sugar-sweetened beverage intake. Am J Clin Nutr. (2015) 101:471-7. doi: 10.3945/ajcn.114.095604

45. Jacobs DM, Fuhrmann JC, van Dorsten FA, Rein D, Peters S, van Velzen EJ, et al. Impact of short-term intake of red wine and grape polyphenol extract on the human metabolome. J Agric Food Chem. (2012) 60:3078-85. doi: $10.1021 / \mathrm{jf} 2044247$

46. Lloyd AJ, Beckmann M, Haldar S, Seal C, Brandt K, Draper J. Datadriven strategy for the discovery of potential urinary biomarkers of habitual dietary exposure. Am J Clin Nutr. (2012) 97:377-89. doi: 10.3945/ajcn.112. 048033

47. Garcia-Aloy M, Llorach R, Urpi-Sarda M, Tulipani S, Estruch R, Martínez-González MA, et al. Novel multimetabolite prediction of walnut consumption by a urinary biomarker model in a free-living population: the PREDIMED study. J Proteome Res. (2014) 13:3476-83. doi: $10.1021 /$ pr500425r

48. Krishnan S, Newman JW, Hembrooke TA, Keim NL. Variation in metabolic responses to meal challenges differing in glycemic index in healthy women: is it meaningful? Nutr Metabol. (2012) 9:26. doi: 10.1186/1743-7075-9-26

49. Wang TT, Edwards AJ, Clevidence BA. Strong and weak plasma response to dietary carotenoids identified by cluster analysis and linked to beta-carotene 15, 15'-monooxygenase 1 single nucleotide polymorphisms. J Nutr Biochem. (2013) 24:1538-46. doi: 10.1016/j.jnutbio.2013.01.001

50. Li K, Brennan L, McNulty BA, Bloomfield JF, Duff DJ, Devlin NF, et al. Plasma fatty acid patterns reflect dietary habits and metabolic health: a cross-sectional study. Mol Nutr Food Res. (2016) 60:2043-52. doi: 10.1002/mnfr.201500711

51. Moazzami AA, Shrestha A, Morrison DA, Poutanen K, Mykkänen H. Metabolomics reveals differences in postprandial responses to breads and fasting metabolic characteristics associated with postprandial insulin demand in postmenopausal women. J Nutr. (2014) 144:807-14. doi: $10.3945 /$ jn. 113.188912 
52. Andersen M-BS, Kristensen M, Manach C, Pujos-Guillot E, Poulsen SK, Larsen TM, et al. Discovery and validation of urinary exposure markers for different plant foods by untargeted metabolomics. Anal Bioanal Chem. (2014) 406:1829-44. doi: 10.1007/s00216-013-7498-5

53. Bouchard-Mercier A, Rudkowska I, Lemieux S, Couture P, Vohl M-C. The metabolic signature associated with the Western dietary pattern: a crosssectional study. Nutr J. (2013) 12:158. doi: 10.1186/1475-2891-12-158

54. Brennan L. Metabolomics in nutrition research: current status and perspectives. Biochem Soc Trans. (2013) 41:670-3. doi: 10.1042/BST20120350

55. Praticò G, Gao Q, Scalbert A, Vergères G, Kolehmainen M, Manach C, et al. Guidelines for Biomarker of Food Intake Reviews (BFIRev): how to conduct an extensive literature search for biomarker of food intake discovery. Genes Nutr. (2018) 13:3. doi: 10.1186/s12263-018-0592-8

56. Myint T, Fraser GE, Lindsted KD, Knutsen SF, Hubbard RW, Bennett HW. Urinary 1-methylhistidine is a marker of meat consumption in Black and in White California Seventh-day Adventists. Am J Epidemiol. (2000) 152:752-5. doi: 10.1093/aje/152.8.752

57. Paquette M, Larqué ASM, Weisnagel S, Desjardins Y, Marois J, Pilon G, et al. Strawberry and cranberry polyphenols improve insulin sensitivity in insulin-resistant, non-diabetic adults: a parallel, double-blind, controlled and randomised clinical trial. Br J Nutr. (2017) 117:519-31. doi: 10.1017/S0007114517000393

58. Allam-Ndoul B, Guénard F, Garneau V, Cormier H, Barbier O, Pérusse L, et al. Association between metabolite profiles, metabolic syndrome and obesity status. Nutrients. (2016) 8:324. doi: 10.3390/nu8060324

59. Bakker GC, Van Erk MJ, Pellis L, Wopereis S, Rubingh CM, Cnubben NH, et al. An antiinflammatory dietary mix modulates inflammation and oxidative and metabolic stress in overweight men: a nutrigenomics approach. Am J Clin Nutr. (2010) 91:1044-59. doi: 10.3945/ajcn.2009.28822

60. O’Sullivan A, Gibney MJ, Brennan L. Dietary intake patterns are reflected in metabolomic profiles: potential role in dietary assessment studies. Am J Clin Nutr. (2010) 93:314-21. doi: 10.3945/ajcn.110.000950

61. Peré-Trepat E, Ross AB, Martin F-P, Rezzi S, Kochhar S, Hasselbalch AL, et al. Chemometric strategies to assess metabonomic imprinting of food habits in epidemiological studies. Chemometrics Intell Lab Syst. (2010) 104:95-100. doi: 10.1016/j.chemolab.2010.06.001

62. Menni C, Zhai G, MacGregor A, Prehn C, Römisch-Margl W, Suhre $\mathrm{K}$, et al. Targeted metabolomics profiles are strongly correlated with nutritional patterns in women. Metabolomics. (2013) 9:506-14. doi: 10.1007/s11306-012-0469-6

63. O'Gorman A, Morris C, Ryan M, O'Grada C, Roche H, Gibney E, et al. Habitual dietary intake impacts on the lipidomic profile. J Chromatogr B. (2014) 966:140-6. doi: 10.1016/j.jchromb.2014.01.032

64. Floegel A, Von Ruesten A, Drogan D, Schulze M, Prehn C, Adamski J, et al. Variation of serum metabolites related to habitual diet: a targeted metabolomic approach in EPIC-Potsdam. Eur J Clin Nutr. (2013) 67:1100. doi: 10.1038/ejcn.2013.147

65. Vázquez-Fresno R, Llorach R, Perera A, Mandal R, Feliz M, Tinahones FJ, et al. Clinical phenotype clustering in cardiovascular risk patients for the identification of responsive metabotypes after red wine polyphenol intake. J Nutr Biochem. (2016) 28:114-20. doi: 10.1016/j.jnutbio.2015. 10.002

66. Zubair N, Kuzawa CW, Lee NR, McDade TW, Adair LS. Clustering and determinants of cardiometabolic risk factors among Filipino young adults. Asia Pacific J Clin Nutr. (2014) 23:148-58. doi: 10.6133/apjen.2014. 23.1.06

67. Zubair N, Kuzawa CW, McDade TW, Adair LS. Cluster analysis reveals important determinants of cardiometabolic risk patterns in Filipino women. Asia Pacific J Clin Nutr. (2012) 21:271.

68. van Bochove K, van Schalkwijk DB, Parnell LD, Lai C-Q, Ordovás JM, de Graaf AA, et al. Clustering by plasma lipoprotein profile reveals two distinct subgroups with positive lipid response to fenofibrate therapy. PLoS ONE. (2012) 7:e38072. doi: 10.1371/journal.pone.0038072

69. O’sullivan A, Gibney MJ, Connor AO, Mion B, Kaluskar S, Cashman KD, et al. Biochemical and metabolomic phenotyping in the identification of a vitamin D responsive metabotype for markers of the metabolic syndrome. Mol Nutr Food Res. (2011) 55:679-90. doi: 10.1002/mnfr.201000458
70. Frazier-Wood AC, Glasser S, Garvey WT, Kabagambe EK, Borecki IB, Tiwari $\mathrm{HK}$, et al. A clustering analysis of lipoprotein diameters in the metabolic syndrome. Lipids Health Dis. (2011) 10:237. doi: 10.1186/1476-511X-10-237

71. Tzeng C-R, Chang Y-cI, Chang Y-c, Wang C-W, Chen C-H, Hsu M-I. Cluster analysis of cardiovascular and metabolic risk factors in women of reproductive age. Fertil Steril. (2014) 101:1404-10. e1. doi: 10.1016/j.fertnstert.2014.01.023

72. Wilcox M, Li Q, Sun Y, Stang P, Berlin J, Wang D. Genome-wide association study for empirically derived metabolic phenotypes in the Framingham Heart Study offspring cohort. BMC Proc. (2009) 3(Suppl. 7):S53.

73. Wilcox MA, Wyszynski DF, Panhuysen CI, Ma Q, Yip A, Farrell J, et al. Empirically derived phenotypic subgroups-qualitative and quantitative trait analyses. BMC Genet. 4(Suppl 1):S15. doi: 10.1186/1471-2156-4-S1-S15

74. Mäkinen VP, Soininen P, Forsblom C, Parkkonen M, Ingman P, Kaski $\mathrm{K}$, et al. $1 \mathrm{H}$ NMR metabonomics approach to the disease continuum of diabetic complications and premature death. Mol Syst Biol. (2008) 4:167. doi: $10.1038 / \mathrm{msb} 4100205$

75. Morris C, O’Grada C, Ryan M, Roche HM, Gibney MJ, Gibney $\mathrm{ER}$, et al. Identification of differential responses to an oral glucose tolerance test in healthy adults. PLoS ONE. (2013) 8:e72890. doi: 10.1371/journal.pone.0072890

76. Ventura AK, Loken E, Birch LL. Risk profiles for metabolic syndrome in a nonclinical sample of adolescent girls. Pediatrics. (2006) 118:2434-42. doi: $10.1542 /$ peds.2006-1527

77. Bouwman J, Vogels JT, Wopereis S, Rubingh CM, Bijlsma S, van Ommen B. Visualization and identification of health space, based on personalized molecular phenotype and treatment response to relevant underlying biological processes. BMC Med Genomics. (2012) 5:1. doi: 10.1186/1755-8794-5-1

78. Houston M. The role of noninvasive cardiovascular testing, applied clinical nutrition and nutritional supplements in the prevention and treatment of coronary heart disease. Ther Adv Cardiovasc Dis. (2018) 12:85-108. doi: $10.1177 / 1753944717743920$

79. Riedl A, Gieger C, Hauner H, Daniel H, Linseisen J. Metabotyping and its application in targeted nutrition: an overview. Br J Nutr. (2017) 117:1631-44. doi: $10.1017 /$ S0007114517001611

80. Sébédio J-L. Metabolomics, nutrition, and potential biomarkers of food quality, intake, and health status. Adv Food Nutr Res. (2017) 82:83-116. doi: 10.1016/bs.afnr.2017.01.001

81. Valdes AM, Walter J, Segal E, Spector TD. Role of the gut microbiota in nutrition and health. BMJ. (2018) 2018:361. doi: 10.1136/bmj.k2179

82. Kang JX. Gut microbiota and personalized nutrition. Lifestyle Genomics. (2013) 6:I-II. doi: 10.1159/000353144

83. Lynch SV, Pedersen O. The human intestinal microbiome in health and disease. N Engl J Med. (2016) 375:2369-79. doi: 10.1056/NEJMra16 00266

84. Schmidt TSB, Raes J, Bork P. The human gut microbiome: from association to modulation. Cell. (2018) 172:1198-215. doi: 10.1016/j.cell.2018.02.044

85. Byndloss MX, Baumler AJ. The germ-organ theory of noncommunicable diseases. Nat Rev Microbiol. (2018) 16:103-10. doi: $10.1038 /$ nrmicro. 2017.158

86. den Besten G, van Eunen K, Groen AK, Venema K, Reijngoud DJ, Bakker $\mathrm{BM}$. The role of short-chain fatty acids in the interplay between diet, gut microbiota, and host energy metabolism. J Lipid Res. (2013) 54:2325-40. doi: 10.1194/jlr.R036012

87. Velazquez OC, Lederer HM, Rombeau JL. Butyrate and the colonocyte. Production, absorption, metabolism, and therapeutic implications. Adv Exp Med Biol. (1997) 427:123-34.

88. Mathews AT, Famodu OA, Olfert MD, Murray PJ, Cuff CF, Downes MT, et al. Efficacy of nutritional interventions to lower circulating ceramides in young adults: FRUVEDomic pilot study. Physiol Rep. (2017) 5:e13329. doi: 10.14814/phy2.13329

89. Koeth RA, Wang Z, Levison BS, Buffa JA, Org E, Sheehy BT, et al. Intestinal microbiota metabolism of L-carnitine, a nutrient in red meat, promotes atherosclerosis. Nat Med. (2013) 19:576. doi: 10.1038/nm.3145

90. Tang WH, Wang Z, Levison BS, Koeth RA, Britt EB, Fu X, et al. Intestinal microbial metabolism of phosphatidylcholine and cardiovascular risk. $N$ Engl J Med. (2013) 368:1575-84. doi: 10.1056/NEJMoa1109400 
91. Rohrmann S, Overvad K, Bueno-de-Mesquita HB, Jakobsen MU, Egeberg $\mathrm{R}$, Tjønneland A, et al. Meat consumption and mortality-results from the European Prospective Investigation into Cancer and Nutrition. BMC Med. (2013) 11:63. doi: 10.1186/1741-7015-11-63

92. Suez J, Korem T, Zeevi D, Zilberman-Schapira G, Thaiss CA, Maza O, et al. Artificial sweeteners induce glucose intolerance by altering the gut microbiota. Nature. (2014) 514:181. doi: 10.1038/nature13793

93. Bokulich NA, Blaser MJ. A bitter aftertaste: unintended effects of artificial sweeteners on the gut microbiome. Cell Metabol. (2014) 20:701-3. doi: 10.1016/j.cmet.2014.10.012

94. Feehley T, Nagler CR. Health: the weighty costs of non-caloric sweeteners. Nature. (2014) 514:176. doi: 10.1038/nature13752

95. Gibson GR, Hutkins R, Sanders ME, Prescott SL, Reimer RA, Salminen SJ, et al. Expert consensus document: the International Scientific Association for Probiotics and Prebiotics (ISAPP) consensus statement on the definition and scope of prebiotics. Nat Rev Gastroenterol Hepatol. (2017) 14:491-502. doi: 10.1038/nrgastro.2017.75

96. Gentile CL, Weir TL. The gut microbiota at the intersection of diet and human health. Science. (2018) 362:776-80. doi: 10.1126/science.aau5812

97. B.Beserra TS, Fernandes R, do Rosario VA, Mocellin MC, Kuntz MGF, Trindade EBSM. A systematic review and meta-analysis of the prebiotics and synbiotics effects on glycaemia, insulin concentrations and lipid parameters in adult patients with overweight or obesity. Clin Nutr. (2015) 34:845-58. doi: 10.1016/j.clnu.2014.10.004

98. Ford AC, Harris LA, Lacy BE, Quigley EMM, Moayyedi P. Systematic review with meta-analysis: the efficacy of prebiotics, probiotics, synbiotics and antibiotics in irritable bowel syndrome. Aliment Pharmacol Ther. (2018) 48:1044-60. doi: 10.1111/apt.15001

99. Rosario D, Benfeitas R, Bidkhori G, Zhang C, Uhlen M, Shoaie S, et al. Understanding the representative gut microbiota dysbiosis in metformintreated type 2 diabetes patients using genome-scale metabolic modeling. Front Physiol. (2018) 9:775. doi: 10.3389/fphys.2018.00775

100. Kovatcheva-Datchary P, Nilsson A, Akrami R, Ying Lee S, De Vadder F, Arora $\mathrm{T}$, et al. Dietary fiber-induced improvement in glucose metabolism is associated with increased abundance of prevotella. Cell Metabol. (2015) 22:971-82. doi: 10.1016/j.cmet.2015.10.001

101. Flint HJ, Duncan SH, Louis P. The impact of nutrition on intestinal bacterial communities. Curr Opin Microbiol. (2017) 38:59-65. doi: 10.1016/j.mib.2017.04.005

102. Suez J, Elinav E. The path towards microbiome-based metabolite treatment. Nat Microbiol. (2017) 2:17075. doi: 10.1038/nmicrobiol.2017.75

103. Shoaie S, Ghaffari P, Kovatcheva-Datchary P, Mardinoglu A, Sen P, Pujos-Guillot E, et al. Quantifying diet-induced metabolic changes of the human gut microbiome. Cell Metabol. (2015) 22:320-31. doi: 10.1016/j.cmet.2015.07.001

104. Griffin NW, Ahern PP, Cheng J, Heath AC, Ilkayeva O, Newgard CB, et al. Prior dietary practices and connections to a human gut microbial metacommunity alter responses to diet interventions. Cell Host Microbe. (2017) 21:84-96. doi: 10.1016/j.chom.2016.12.006

105. Zmora N, Zilberman-Schapira G, Suez J, Mor U, Dori-Bachash M, Bashiardes $\mathrm{S}$, et al. Personalized gut mucosal colonization resistance to empiric probiotics is associated with unique host and microbiome features. Cell. (2018) 174:1388-405. e21. doi: 10.1016/j.cell.2018.08.041

106. Thaiss CA, Itav S, Rothschild D, Meijer MT, Levy M, Moresi C, et al. Persistent microbiome alterations modulate the rate of post-dieting weight regain. Nature. (2016) 540:544. doi: 10.1038/nature20796

107. Fito M, Konstantinidou V. Nutritional genomics and the mediterranean diet's effects on human cardiovascular health. Nutrients. (2016) 8:218. doi: 10.3390/nu8040218

108. Konstantinidou V, Covas MI, Sola R, Fito M. Up-to date knowledge on the in vivo transcriptomic effect of the Mediterranean diet in humans. Mol Nutr Food Res. (2013) 57:772-83. doi: 10.1002/mnfr.2012 00613

109. Llorente-Cortes V, Estruch R, Mena MP, Ros E, Gonzalez MA, Fito M, et al. Effect of Mediterranean diet on the expression of pro-atherogenic genes in a population at high cardiovascular risk. Atherosclerosis. (2010) 208:442-50. doi: 10.1016/j.atherosclerosis.2009.08.004

110. Lee S, Park Y, Zuidema MY, Hannink M, Zhang C. Effects of interventions on oxidative stress and inflammation of cardiovascular diseases. World $J$ Cardiol. (2011) 3:18-24. doi: 10.4330/wjc.v3.i1.18

111. Berdasco M, Esteller M. Clinical epigenetics: seizing opportunities for translation. Nat Rev Genet. (2019) 20:109-27. doi: 10.1038/s41576-018-0074-2

112. Hubel C, Marzi SJ, Breen G, Bulik CM. Epigenetics in eating disorders: a systematic review. Mol Psychiatry. (2018) 1476-5578. doi: 10.1038/s41380-018-0254-7. [Epub ahead of print].

113. Szarc vel Szic K, Declerck K, Vidakovic M, Vanden Berghe W. From inflammaging to healthy aging by dietary lifestyle choices: is epigenetics the key to personalized nutrition? Clin Epigenet. (2015) 7:33. doi: 10.1186/s13148-015-0068-2

114. Lillycrop KA, Hoile SP, Grenfell L, Burdge GC. DNA methylation, ageing and the influence of early life nutrition. Proc Nutr Soc. (2014) 73:413-21. doi: 10.1017/S0029665114000081

115. Petersen AK, Zeilinger S, Kastenmuller G, Romisch-Margl W, Brugger M, Peters A, et al. Epigenetics meets metabolomics: an epigenome-wide association study with blood serum metabolic traits. Hum Mol Genet. (2014) 23:534-45. doi: 10.1093/hmg/ddt430

116. Badimon L, Vilahur G, Padro T. Systems biology approaches to understand the effects of nutrition and promote health. Br J Clin Pharmacol. (2017) 83:38-45. doi: 10.1111/bcp.12965

117. Panagiotou G, Nielsen J. Nutritional systems biology: definitions and approaches. Ann Rev Nutr. (2009) 29:329-39. doi: 10.1146/annurev-nutr-080508-141138

118. Zheng T, Ni Y, Li J, Chow BKC, Panagiotou G. Designing dietary recommendations using system level interactomics analysis and networkbased inference. Front Physiol. (2017) 8:753. doi: 10.3389/fphys.2017.00753

119. Jensen K, Ni Y, Panagiotou G, Kouskoumvekaki I. Developing a molecular roadmap of drug-food interactions. PLoS Comput Biol. (2015) 11:e1004048. doi: 10.1371/journal.pcbi.1004048

120. Nielsen DE, El-Sohemy A. Disclosure of genetic information and change in dietary intake: a randomized controlled trial. PLoS ONE. (2014) 9:e112665. doi: 10.1371/journal.pone.0112665

121. Ordovas JM, Ferguson LR, Tai ES, Mathers JC. Personalised nutrition and health. BMJ. (2018) 2018:361. doi: 10.1136/bmj.k2173

122. Ozdemir V, Kolker E. Precision nutrition 4.0: a big data and ethics foresight analysis-convergence of agrigenomics, nutrigenomics, nutriproteomics, and nutrimetabolomics. Omics. (2016) 20:69-75. doi: 10.1089/omi.2015.0193

123. Tebani A, Afonso C, Marret S, Bekri S. Omics-based strategies in precision medicine: toward a paradigm shift in inborn errors of metabolism investigations. Int J Mol Sci. (2016) 2016:17. doi: 10.3390/ijms170 91555

Conflict of Interest Statement: The authors declare that the research was conducted in the absence of any commercial or financial relationships that could be construed as a potential conflict of interest.

Copyright (c) 2019 Tebani and Bekri. This is an open-access article distributed under the terms of the Creative Commons Attribution License (CC BY). The use, distribution or reproduction in other forums is permitted, provided the original author(s) and the copyright owner(s) are credited and that the original publication in this journal is cited, in accordance with accepted academic practice. No use distribution or reproduction is permitted which does not comply with these terms. 